Indonesian Journal of Physics

Vol 22 No. 1, January 2011

\title{
Resistivtiy Structure in Kamojang Geothermal Field Derived from CSAMT Data
}

\author{
Enjang Jaenal Mustopa, Wahyu Srigutomo, Doddy Sutarno and Umar Fauzi \\ Physics of the Earth \& Complex System, \\ Faculty of Mathematics and Natural Sciences, \\ Bandung Institute of Technology, Indonesia \\ e-mail:enjang@fi.itb.ac.id
}

Received 18 October 2010, Accepted 10 December 2010

\begin{abstract}
Controlled-source audio frequency magnetotelluric (CSAMT) survey consisting of 60 soundings has been carried out in the Kamojang geothermal field to delineate resistivity structure correlated to the present geothermal reservoir. The transmitter site was located about $3-5 \mathrm{~km}$ in the south-west of the survey area. The sounding sites were distributed irregularly and the distance between each of them varied from 200 to $500 \mathrm{~m}$, covering the Kamojang Geothermal area. The two dimensional (2D) inversion scheme was applied to interpret the CSAMT data. The results show that the subsurface resistivity structures in the Kamojang geothermal field consists of three types of resistivity features correlated to the existing geothermal reservoir in the area, that is, the overburden (first layer) having resistivity value of 30 - $150 \mathrm{ohm} . \mathrm{m}$ and thickness of 30 to $100 \mathrm{~m}$ overlaying the intermediate (second) layer which has an extremely low resistivity of $3-10$ ohm.m with $500-1200$ m thick. This low resistivity layer can be considered as a hydrothermal alteration zone comprising the impermeable layer or sealing cap rock. Finally, the third layer which is relatively more resistive than the second layer with resistivity of $30-100$ ohm-m. From the 3D view of the low resistivity anomaly $(<10 \mathrm{ohm} . \mathrm{m})$ considered as a hydrothermal alteration zone, it is obtained that altered zone is deep in the south-west and becomes shallow in the north-east of the area.
\end{abstract}

Keywords: CSAMT, 2D inversion, Geothermal Reservoir, Kamojang Geothermal Field

\section{Introduction}

A Controlled-source audio frequency magnetotelluric (CSAMT) measurement, in the operating frequency range of $0.25 \mathrm{~Hz}$ to $8192 \mathrm{~Hz}$, has been conducted in the Kamojang geothermal field (Figure 1). The location of transmitter was about $3-5$ $\mathrm{km}$ in the southwest from the survey area. The sounding sites were distributed irregularly and the distance between each of them varied from 200 to 500 $\mathrm{m}$, covering the Kamojang Geothermal area. (Figure 2). The purpose of the measurements is to demonstrate the capability of the CSAMT method used for a geothermal exploration by locating an anomalous low resistivity zone associated with the existence of geothermal reservoir in the area.

The Kamojang geothermal field which is located in Garut, West Java, has several wells generating electricity since 1983 . The CSAMT survey area is geographically between $07^{\circ} 10^{\prime} 30^{\prime \prime}-07^{\circ}$ 07'30" South latitude and $107^{\circ} 45^{\prime} 30^{\prime \prime}-107^{\circ} 49^{\prime} 30^{\prime}$ ' East longitude or at UTM (Universal Transverse Mercator) zone 48 between 803,739.46 - 811,142.44 East and in the range of 9,205,994.45 - 9,211,483.58 North. It has topographic elevations ranging from 1400 to $1800 \mathrm{~m}$ above sea level (ASL). Pertamina has been drilled more than 70 wells in the field since 1983 and it has been producing a sufficient steam of the vapor-dominated resources for generating electricity with the total installed capacity of about $200 \mathrm{MW}^{1)}$.

The CSAMT method, developed by Goldstein and Strangway ${ }^{2}$, utilizes a grounded electric dipole as an artificial source instead of a natural electromagnetic source which is used in the magnetotelluric (MT) method. The advantages of this technique are that the polarization of the fields can be selected by the orientation of the transmitting antenna and the signal strengths do not depend on the natural electromagnetic source as in MT method. I $n$ the CSAMT method, the non-plane wave nature of the source limits the interpretation of the data if we use MT interpretation scheme. Recognizing this, the CSAMT measurement must be carried out at a distance greater than $3-5$ skin depths from the transmitter site where the plane wave approximation is valid. However, the CSAMT data still contain some near-field effect when the frequency of the transmitter signal is low (correlated to deeper depth of penetration). Therefore, correction for a near-field effect is necessary before applying the MT interpretation technique ${ }^{3 \text { ) }}$. Since the measurements were made using the electric field along the transversal direction of the geological strike, the data was assumed corresponding to the transverse magnetic (TM) mode ${ }^{4}$.

The typical structure of geothermal system is schematically presented in Figure 3. The cooler upper zones are characterized by alteration of electrical conductive layer that is formed at temperatures above $70{ }^{\circ} \mathrm{C}$. At higher temperatures, illite of less conductive layer becomes interlayered with smectite. The proportion of illite increases with the temperature, forming about $70 \%$ of the mixed-layer clay at $180{ }^{\circ} \mathrm{C}$. Above this temperature, the smectite content continued to decrease, and pure illite commonly appears at greater than $220{ }^{\circ} \mathrm{C}^{5)}$. 


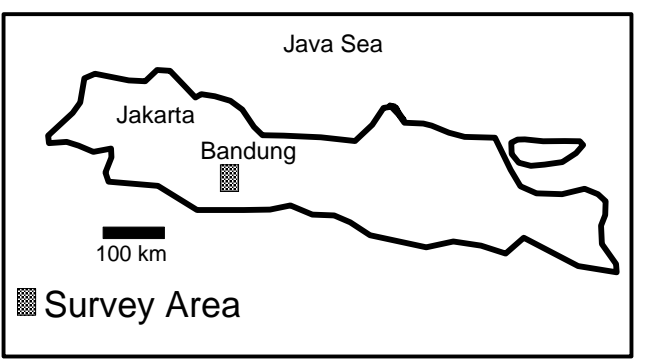

Figure 1. The location of the Kamojang geothermal field.

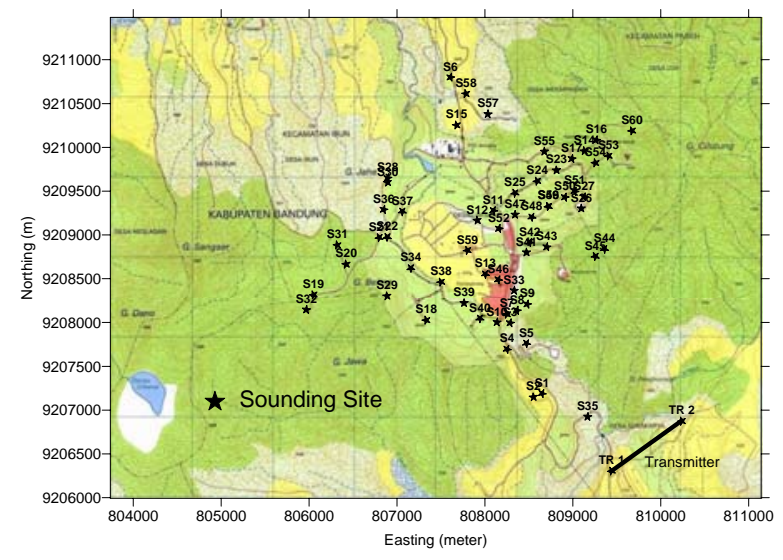

Figure 2. The location of the CSAMT survey in Kamojang field.

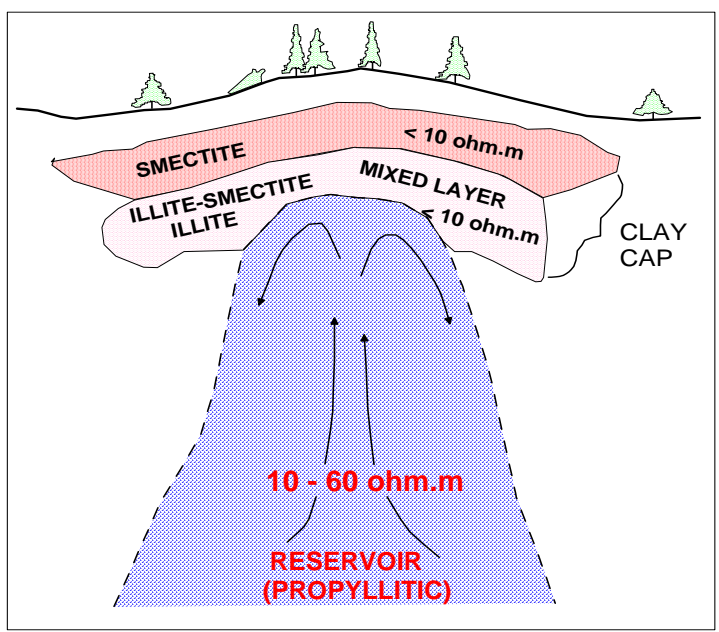

Figure 3. A generalized geothermal system ${ }^{6}$.

\section{CSAMT Theory}

Basic theoretical principle for CSAMT theory can be described in terms of Maxwell's equations. Since CSAMT measurements employ a grounded electric dipole, in a source free region, the electric and magnetic field can be decomposed into terms of Schelkunoff potential $\mathbf{A}$ and $\mathbf{F}^{7)}$,

$$
\begin{aligned}
\mathbf{E}= & -\nabla \times F_{z}(x, y, x, \omega) \mathbf{z}-(i \omega \mu) A_{z} \mathbf{z} \\
& +\frac{1}{(\sigma+i \omega \varepsilon)} \nabla\left(\nabla \cdot A_{z} \mathbf{z}\right)
\end{aligned}
$$

$$
\begin{aligned}
\mathbf{H}= & -\nabla \times A_{z}(x, y, x, \omega) \mathbf{z}-(\sigma+i \omega \varepsilon) F_{z} \mathbf{z} \\
& +\frac{1}{i \omega \mu} \nabla\left(\nabla \cdot A_{z} \mathbf{z}\right)
\end{aligned}
$$

where $\mathbf{E}$ is the electric field intensity, $\mathbf{H}$ is the magnetic field intensity, $\mathbf{z}$ is the unit vector in the vertical direction, $\sigma$ is the electrical conductivity, $\varepsilon$ is the electrical permittivity, $\mu$ is the magnetic permeability, and $\omega$ is the angular frequency.

The general solutions of a tangential component of electric field $\left(E_{\phi}\right)$ and a radial component of magnetic field $\left(H_{r}\right)$ from equations (1) and (2) are expressed in cylindrical coordinates ${ }^{8)}$ as

$$
\begin{aligned}
& E_{\phi}=\frac{I d l \sin \phi}{2 \pi \sigma r^{3}}\left[2-e^{-i k r}(1+i k r)\right] \\
& H_{r}=\frac{I d l \sin \phi}{2 \pi r^{2}} \\
& \left\{\begin{array}{l}
3 I_{1}\left(\frac{i k r}{2}\right) K_{1}\left(\frac{i k r}{2}\right) \\
+\frac{i k r}{2}\left[I_{1}\left(\frac{i k r}{2}\right) K_{0}\left(\frac{i k r}{2}\right)-I_{0}\left(\frac{i k r}{2}\right) K_{1}\left(\frac{i k r}{2}\right)\right]
\end{array}\right\}
\end{aligned}
$$

where $d l$ is the dipole length, $r$ is the source-sounding distance, and $I_{m}$ and $K_{m}$ are modified Bessel function of the $m$-th order.

Far from dipole source, equations (3) and (4) approach the following limits, with quasi-static assumption,

$$
\begin{aligned}
& E_{\phi} \approx \frac{I d l \sin \phi}{\pi \sigma r^{3}} \\
& H_{r} \approx \frac{I d l \sin \phi}{\pi \sqrt{\mu \sigma \omega} r^{3}} e^{\frac{-i \pi}{4}}
\end{aligned}
$$

For a homogenous earth, the azimuthal $E$-field is independent of frequency and directly proportional to resistivity. The horizontal $H$-field components are frequency-dependent and a function of the square root of ground resistivity. Hence $H$-field is fully responsive to resistivity change and frequency.

As shown in equations (5) and (6) the horizontal fields in the far-field zone all decay as $1 / r^{3}$, thus the far-field apparent resistivity can be determined by measuring the perpendicular $E$ and $H$, that is

$$
\rho_{a}=\frac{1}{\mu \omega}\left|\frac{E_{\phi}}{H_{r}}\right|^{2}
$$

which is commonly called the Cagniard resistivity or MT apparent resistivity.

Because of the need to minimize the transmitter-receiver separation for maximum signal, the far-filed zone is restricted by this situation; therefore, most CSAMT data sets will contain some near-field and transition zone data. To overcome the source effect problem, a correction technique to CSAMT data should be applied to obtain apparent 
resistivity value equivalent to the far field situation. In this paper, a simple technique to correct near-field CSAMT apparent resistivity, proposed by Yamashita et al. ${ }^{3)}$ is used. The technique suggests that the plane wave apparent resistivity is the apparent resistivity calculated by near field equation for the lower frequency and the apparent resistivity calculated by Cagniard equation for the high frequency.

The 2D inversion has been used for many years to interpret automatically CSAMT data. This technique makes the interpretation more objective and less time-consuming then the trial-and-error approach but it does not yield a unique solution. Nevertheless, a common approach to fitting a 2D CSAMT data set is to construct a cross-section of the area based on prior geological knowledge and the model parameterization to solve for the conductivities by least-square inversion. A 2D inversion scheme using the non-linier conjugate gradients (NLCG) algorithm proposed by Rodi and Mackie $^{9)}$ was applied to the corrected CSAMT data of transverse magnetic mode. The NLCG scheme minimizes an objective function that penalizes data residuals and the second spatial derivatives of the resistivity.

Tikhonov's method defines a regularized solution of the inverse problem to the model that minimize the object function

$$
\Psi(\mathbf{m})=(\mathbf{d}-\mathbf{F}(\mathbf{m}))^{T} \mathbf{V}^{-1}(\mathbf{d}-\mathbf{F}(\mathbf{m}))+\lambda\left\|\mathbf{L}\left(\mathbf{m}-\mathbf{m}_{0}\right)\right\|^{2}
$$

where $\mathbf{d}$ is observed data vector, $\mathbf{m}$ is an unknown model vector, $\mathbf{m}_{o}$ is a priori model, $\mathbf{F}$ is a forward modeling operator, $\mathbf{V}$ is an error covariance matrix, $\mathbf{L}$ is a linier operator, and $\lambda$ is a regularization parameter. Each datum $d_{i}$ is log amplitude or phase of transverse electric (TE) or transverse magnetic (TM) mode of complex apparent resistivity at a particular station and frequency. The model vector is also log resistivity as a function of position $(m(x)=\log \rho(x))$. The Laplacian operator can be written as follow

$$
\left\|\mathbf{L}\left(\mathbf{m}-\mathbf{m}_{o}\right)\right\|^{2}=\int\left(\Delta\left(\mathbf{m}(x)-\mathbf{m}_{0}(x)\right)\right)^{2} d x
$$

NLCG directly solves to minimize the objective function $\psi$ of equation (8). The model sequence is given by

$$
\begin{aligned}
& \Psi\left(m_{j}+\alpha_{j} h_{j}\right)=\min _{\alpha} \Psi\left(m_{j}+\alpha h_{j}\right) \\
& m_{j+1}=m_{j}+\alpha_{j} h_{j} \\
& h_{j}=-C_{j} g_{j}+\beta_{j} h_{j-1}
\end{aligned}
$$

where $\alpha_{j}$ is a size step, $h_{j}$ is a search direction, $C_{j}$ is a preconditioner, $g_{j}$ is a gradient of objective function and $\beta_{j}$ is a scalar calculated as

$$
\beta_{j}=\frac{g_{l}^{T} C_{l}\left(g_{l}-g_{l-1}\right)}{g_{l-1}^{T} C_{l-1} g_{l-1}}
$$

\section{CSAMT Field Survey}

A schematic of the basic equipment configuration of CSAMT field measurement is shown in Figure 4. The transmitter dipole (typically $1-3 \mathrm{~km}$ long) is located far enough from the receiver dipole, which is more than three skin depths at the lowest frequency being used. The receiver setup consists of a 100 - $200 \mathrm{~m}$ long grounded electric dipole oriented parallel to the transmitting dipole for maximum electric field pickup and a high-gain magnetic coil oriented at right angle to the dipole for magnetic field detection. The magnetic coil is centered on this dipole and located on $5-10 \mathrm{~m}$ off line, away from receiver operator, to minimize noise generated by motion of the operator.

The CSAMT measurement, in the operating frequency range of $0.25 \mathrm{~Hz}$ to $8192 \mathrm{~Hz}$, has been conducted in Kamojang geothermal field under the funding of Incentive Program Research from the Ministry of Research and Technology (RISTEK) in the year of 2007. The main electromagnetic equipments used in the survey were the CSAMT survey equipments from Zonge Engineering and Research Organization (GGT-10 and GDP-16).

The measurement was carried out in irregularly grid spacing stations consisting of 60 soundings. The electric dipole source was located $3-6 \mathrm{~km}$ in the southwestern part of the survey as shown in Figure 2.

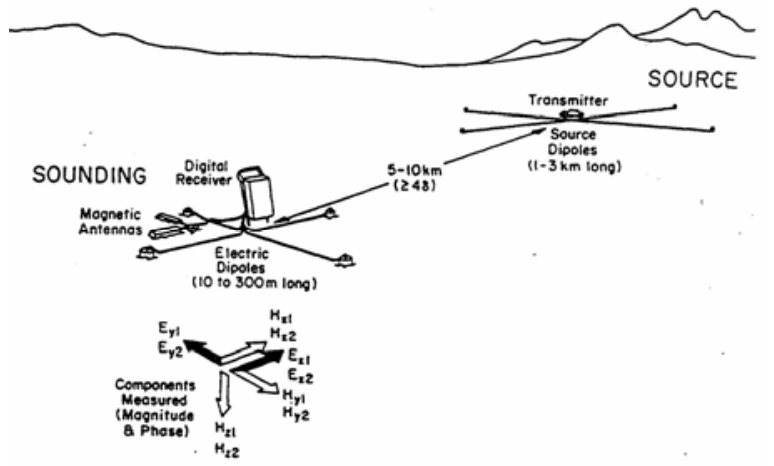

Figure 4. CSAMT field measurement arrangement ${ }^{10)}$

\section{Interpretation of CSAMT Data}

\subsection{Two Dimensional Inversion}

The inversion method relies on forward model calculation into the relationship between observed and real subsurface structure to obtain a reliable solution. In this paper, a two dimensional (2D) inversion technique based on a non-linier conjugate gradient method $^{9)}$ using finite difference discretization was applied to invert the corrected CSAMT data. Since measurements were made using the electric field along the transversal direction of the geological strike and the magnetic field parallel to the strike, it is assumed that the data correspond to the Transverse Magnetic (TM) mode ${ }^{4)}$.

Applying the two dimensional inversion scheme to obtain several resistivity sections, seven line profiles (Line-1 - Line-7) were constructed. The 
location of each line is described in Figure 5. The finite difference meshes used in this inversion consists of $50 \times 40$ nodes and the initial value of the resistivity is 100 ohm-m (homogenous earth model). The inverted data are the apparent and the phase of TM mode. To identify the capability of the $2 \mathrm{D}$ inversion scheme, we display the fitting curve of the observed and the calculated data of the sounding 20 and 31 (Line-1) as shown in the Figure 6. It is identified from the figures that the root mean square (rms) error obtained from the inversion is between $6-7$ percent.

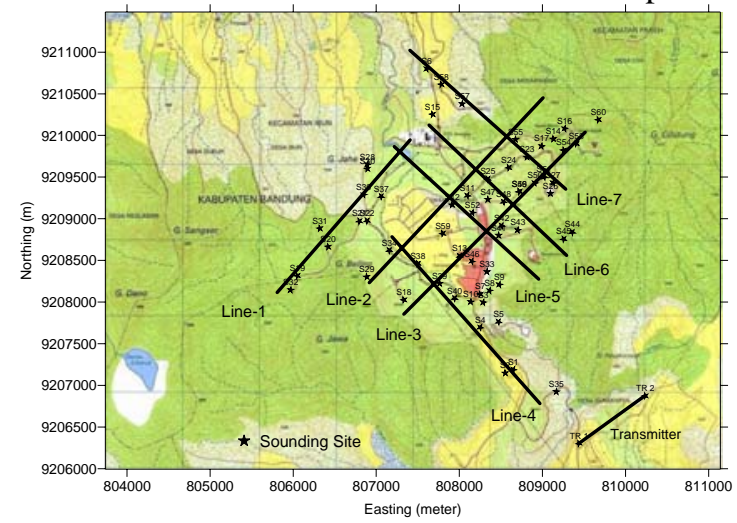

Figure 5. Seven line profiles for 2D inversion analysis.
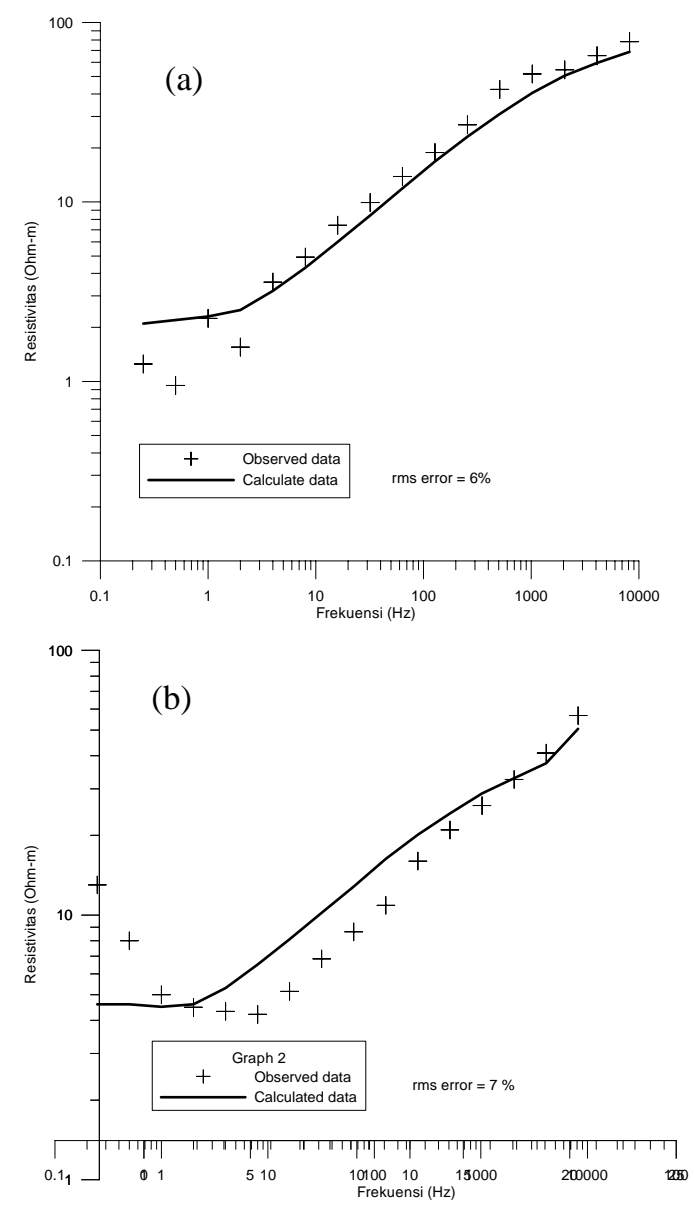

Figure 6. Fitting curve of the observed and the inverted data obtained from $2 \mathrm{D}$ inversion result of a) sounding 20 and b) sounding 31 .
Figure 7 shows 2D inversion results of Line-1 and Line- 2 sections. It is identified from the figure that the resistivity structures in those sections are composed mainly by three types of resistivity structures. The first layer has resistivity of $30-150$ ohm.m within the thickness of $30-100$ meters overlaying an extremely low resistivity zone in the second layer, which has resistivity value of $3-10$ ohm.m and thickness of $500-2000$ meters. This second resistivity structure correlates to a layer of strong hydrothermal alteration zone. The third or bottom layer has resistivity value of $30-100 \mathrm{ohm}-\mathrm{m}$ that is relatively more resistive than the second layer. Moreover, the electrical discontinuity is found below the sounding site S12 on Line-2 in the depth of $500-$ $1000 \mathrm{~m}$ above sea level. Therefore, this zone can be considered as a fault where the fracture type of geothermal reservoir exists in this area.

It is identified from Figure 8.a) that a low resistivity structure beneath the Line-3 along southeast to northwest direction exists in the northeastern part of the area starting from sounding S42. The anomalous low resistivity zone becomes lower and thinner in the northeast than in the southwest. Generally, the subsurface resistivity structure in this section is also composed mainly by three types of resistivity layer, that is, a high resistivity in the first layer $(50-300$ ohm.m), low resistivity in the second layer (1-10 ohm.m) and high resistivity in third layer (60 - 500 ohm.m). Furthermore, from the inspection of Figure 8.b), it is found that anomalous low resistivity zone can not be found in Line-4 (south-east to north-east direction). Consequently, in this section a geothermal reservoir may not exist in the subsurface of the area.

The inversion result of Line-5 is given in Figure 9.a), whose profile orientation is in south-east to north-west direction. The CSAMT data obtained from eight soundings located on and close to this line are used as the observed data in the inversion process. The section shows that the subsurface resistivity structure along this line is identified by three types of resistivity structure. The first layer is characterized by 50 - 300 ohm-m resistivities within 50 - $100 \mathrm{~m}$ depth, followed by a conductive $(1-10 \mathrm{ohm}-\mathrm{m})$ zone in the second layer down to 300 - $1000 \mathrm{~m}$ depth. The conductive layer is interpreted as an impermeable layer consisting of a hydrothermal alteration zone. The third layer is a resistive basement characterized by relatively high resistivity (50 - 300 ohm-m) that may be interpreted as a geothermal reservoir. Moreover, the electrical discontinuity was found below sounding S3 of Line-5 that may be interpreted as a fracture.

The 2D resistivity section of Line- 6 along south-east to north-west direction is presented in Figure 9.b). The low resistivity zone (1 - $10 \mathrm{ohm} . \mathrm{m})$ is concentrated below the sounding S59 at the depth of $1300 \mathrm{~m}$ ASL. Another low resistivity zone is concentrated in the southeast below site S9 at the depth of 1000 m ASL. 
Finally, it is identified from Figure 10 that the low resistivity zone in the section along Line-7, in southeast to north-west direction, is deeper and thicker than that in the north-east. The north-eastern part of this low resistivity zone is intensive and shallower than that in the south-western part. Consequently, the underlying resistive layer correlated to the reservoir zone is shallower in the northeast part.

Generally, the subsurface resistivity structure in the Kamojang geothermal field is appropriate to the typical structure of geothermal system mentioned in the previous section. For that reason, The CSAMT method applied at Kamojang Geothermal Field was successful to locate an anomalously low resistivity zone that may indicate a potential geothermal reservoir.
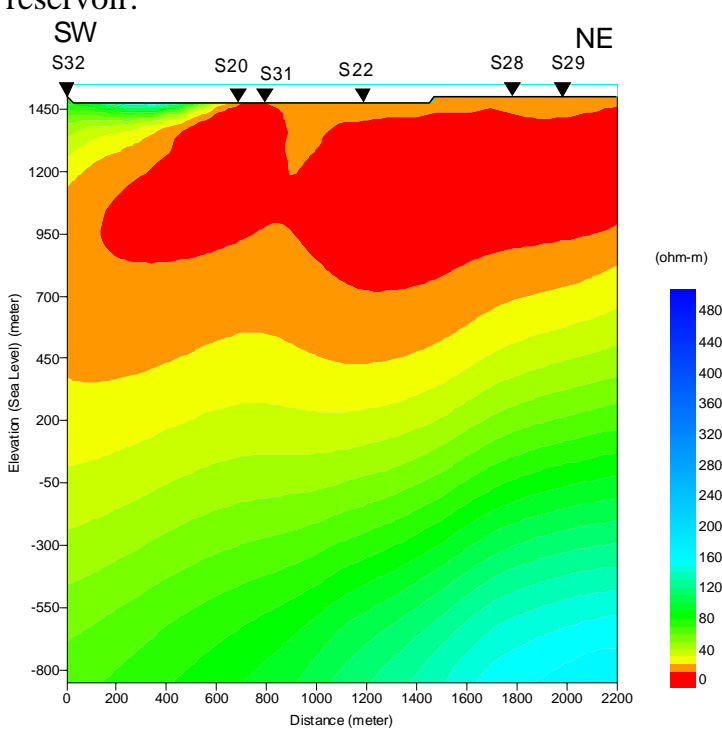

(a)

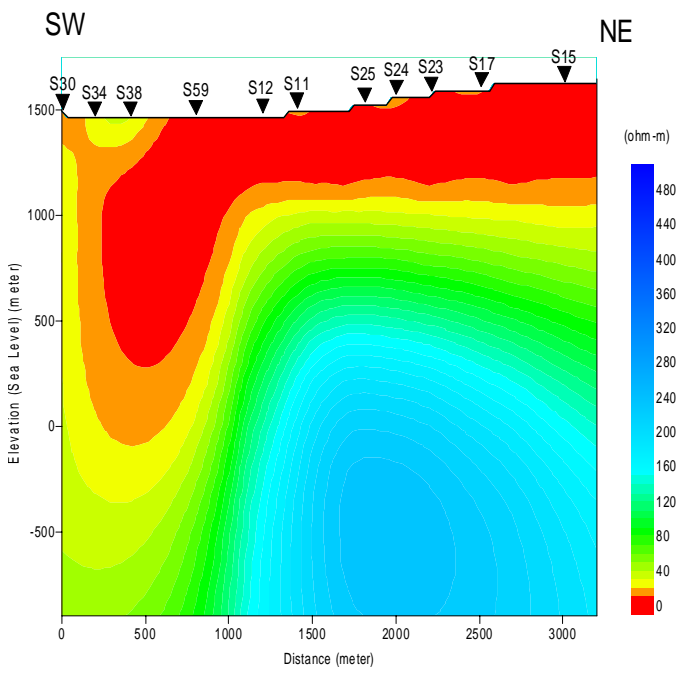

(b)

Figure 7. Resistivity section derived from 2D inversion along a) Line-1 and b) Line-2

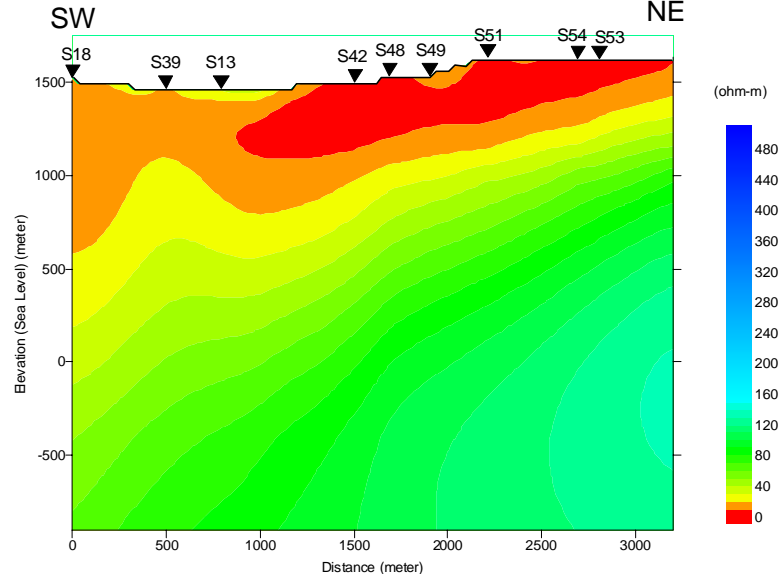

(a)

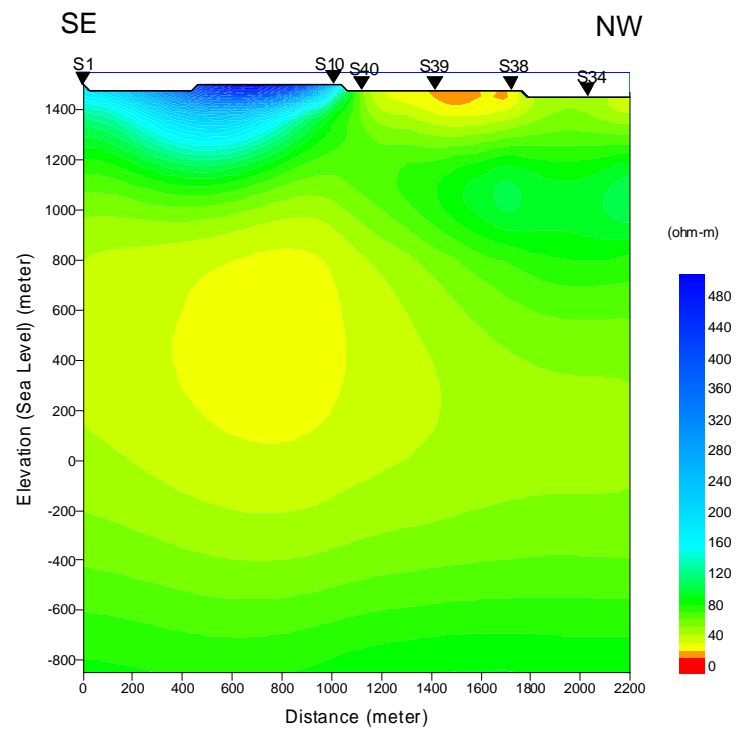

(b)

Figure 8. Resistivity section derived from 2D inversion along a) Line-3 and b) Line-4.

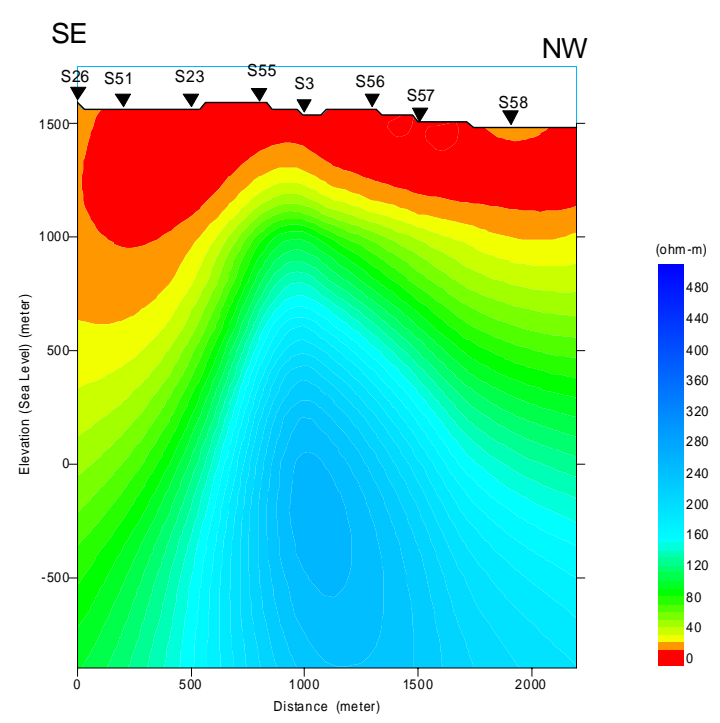

(a) 


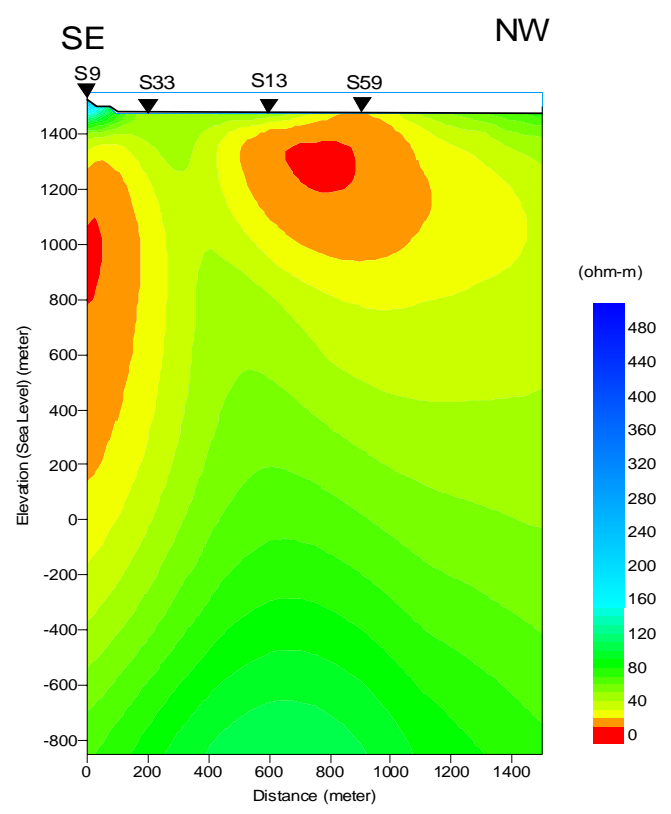

(b)

Figure 9. Resistivity section derived from 2D inversion along a) Line-5 and b) Line-6.

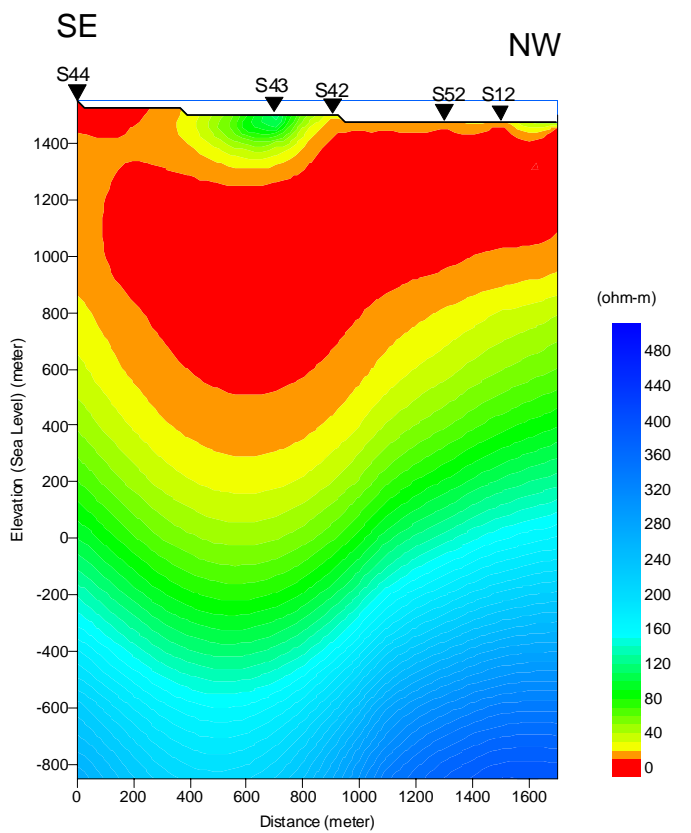

Figure 10. Resistivity section derived from 2D inversion along Line-7.

\subsection{Three Dimensional View}

To understand the resistivity distribution in term of three dimensional (3D) geological structure, the 3D model of resistivity structure was constructed from 2D resistivity sections for all lines (Line-1 Line-7). The 3D view of the resistivity structure and the low resistivity anomaly ( $<10 \mathrm{ohm} . \mathrm{m})$ in the area are shown in Figure 11 and Figure 12, respectively. The figures show that the conductive (second) layer is deeper in the south-west and becomes shallower in the north-east of the investigated area.

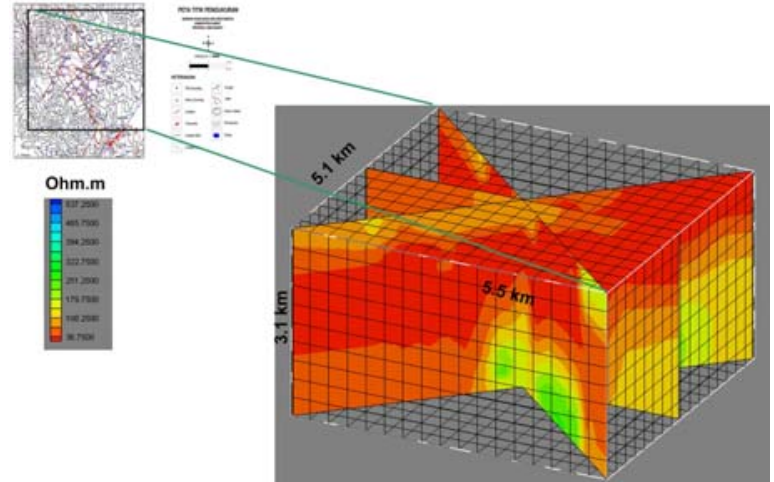

Figure 11 . Resistivity structure in $3 \mathrm{D}$ view obtained from $2 \mathrm{D}$ inversion results

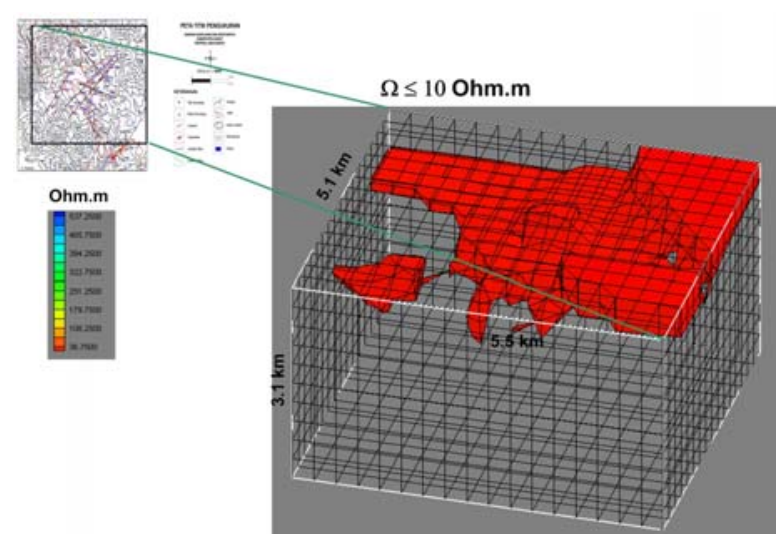

Figure 12 . Resistivity structure in $3 \mathrm{D}$ view of a low resistivity zone (<10 ohm.m).

\section{Discussion and Conclusion}

The CSAMT method applied at Kamojang Geothermal Field was successful to locate an anomalously low resistivity zone that indicates a potential geothermal reservoir. Employing the 2D inversion to CSAMT data, the reasonable resistivity structure correlating to the existing geothermal reservoir has been successfully obtained in Kamojang Geothermal Field.

Generally, the subsurface resistivity structures in Kamojang geothermal field are composed mainly by three types of resistivity feature obtained from 2D inversion results of CSAMT data. The overburden (first layer) has a resistivity of $30-150 \mathrm{ohm}-\mathrm{m}$ and thickness of 30 to $100 \mathrm{~m}$. The intermediate (second) layer has an extremely low resistivity of $3-15$ ohm.m with $500-1200 \mathrm{~m}$ thick. The low resistivity layer as an anomalous feature can be considered as a hydrothermal alteration zone (impermeable layer/cap rock). Finally, the basement (third) layer that is relatively more resistive than the second layer with resistivity of $30-100 \mathrm{ohm}-\mathrm{m}$. It is confirmed from the $3 \mathrm{D}$ model of the low resistivity anomaly $(<10$ ohm.m), that the conductive (second) layer, which correlates to the layer of a hydrothermal alteration zone, is deeper in the south-west and becomes shallower in the north-east of the investigated area. 
This paper demonstrates the capability of the CSAMT method for geothermal explorations. Within the scope of this research, the final results of the method successfully determine the subsurface resistivity structure in the area that importantly characterizes the geothermal system at Kamojang field. One should note that the information of the subsurface structure regarding the existence of the geothermal reservoir in the Kamojang geothermal filed can not be fully understood only using this method to describe the real geological subsurface structures. Further information of other geophysical data interpretations (i.e. gravity and magnetic method) supported by well information (i.e. temperature, losscirculation, permeability, pressure, production rate) as well as geological formation are required for a complete interpretation of the system. Once the integrated information constructed, we can predict the extension of promising area for further geothermal exploitation in the Kamojang geothermal filed.

\section{Acknowledgments}

The authors are grateful to the Incentive Program from the Ministry of Research and Technology (RISTEK) for funding the research in 2007. We also would like to thank Pertamina Geothermal Division for permission to conduct the CSAMT sounding surveys at Kamojang Geothermal Field. Finally, we greatly appreciate the members of CSAMT team of Earth Physics Lab. ITB for their support during the survey in Kamojang in August 2007.

\section{References}

1. S. Sudarman et al., Mapping reservoir permeability with geoelectrical, FMS and spinner data, Kamojang field, Indonesia: Proc. WGC 2000, 2911-2917, 2000.
2. M.A. Goldstein and D. W. Strangway, Audio Frequency Magnetotelluric with Grounded Electric Dipole Source, Geophysics, 40, 669-683, 1975.

3. M. Yamashita, P. G. Hallof, and W. H. Pelton, CSAMT Case Histories with a Multichannel Csamt System and Near-Field Data Correction, 55 ${ }^{\text {th }}$ SEG Annual Convention, 276-278, 1985.

4. Y. Sasaki, Y. Yoshihiro, and K. Matsuo, Resistivity Imaging of Controlled-Source Audiofrequency Magnetotelluric Data, Geophysics, 57, 952-955, 1992.

5. E. Anderson, D. Crosby and G. Ussher, Bullseye! -Simple Resistivity Imaging to Reliably Locate the Geothermal Reservoir, Proc. WGC 2000, 909-914, 2000.

6. J. M. Johnston, L. Pellerin and G. W. Hohmann, Evaluation of Electromagnetic Methods for Geothermal Reservoir Detection, Geothermal Resource Council Transactions, 16, 241-245, 1992.

7. S. H. Ward and G. W. Hohmann, 1988, Electromagnetic theory for geophysical application, in Nabigihan, M. N., Ed., Electromagnetic methods in applied geophysics, Soc. Expl. Geophys, 1988.

8. A.A. Kaufman and G. V. Keller, Frequency and Transient Sounding Method, Elsevier Sci. Publ. Co. Inc., 1983.

9. W. Rodi, and R. L. Mackie, Nonlinear Conjugate Gradients Algorithm for 2-D Magnetotelluric Inversion, Geophys., 66, 174-187, 2001.

10. K. L. Zonge and L. J. Hughes, Controlled Source Audio Frequency Magnetotellurics in Nabigihan, M. N., Ed., Electromagnetic Methods in Applied Geophysics, 2, Application, Part B, Soc. Explor. Geophys., 1991. 